\title{
Redescription of $\dagger$ Cobitis longipectoralis Zhou, 1992 (Cypriniformes: Cobitidae) from late early Miocene of East China
}

\author{
Chen GengJiao \& ChANG MiMan
}

Institute of Vertebrate Paleontology and Palaeoanthropology, Chinese Academy of Sciences, Beijing 100044, China

$\dagger$ Cobitis longipectoralis from the late early Miocene of East China is not only the most informative and best-preserved early cobitid fossil known thus far but also the only and earliest cobitid fossil from East Asia.

The family Cobitidae is a group of small, bottom dwelling, primary freshwater fishes. They are widely distributed in Eurasia and Morocco, with the greatest diversity in southern Asia. However, known fossil cobitids are scarce, and only include a few species of Cobitis and a species of Sabanejewia. Most of the materials consist of either detached suborbital spines or poorly preserved skeletons with little information about the suborbital spines. $†$ Cobitis longipectoralis Zhou, 1992, from the late early Miocene of Shanwang, Shandong Province, eastern China, is the only species with well preserved specimens.

In this work, $\dagger$ Cobitis longipectoralis Zhou, 1992, was restudied based on additional information derived from a new specimen, as well as those collected previously but had recently been further prepared. The study is reported in Issue 53 (July, 2010) of SCIENCE CHINA Earth Sciences because of its significant research value.

The specimens of $†$ Cobitis longipectoralis show that it is a Cobitis with standard length about eight times the body depth; nine pectoral fin rays; total number of vertebrae about 43; number of abdominal vertebrae about equal to those of caudal ones; suborbital spine stout, mediocaudal process slightly curved and long, laterocaudal process short and less than half of the mediocaudal process in length, medial process prominent; second pectoral fin ray in adult male thickened and elongated, with an approximately square-shaped lamina cirrularis at its base; origin of dorsal fin midway between snout and caudal fin bases or slightly posteriorly situated; insertion of pelvic fin opposed to the middle of the dorsal fin base.

Known fossil cobitids are scarce, and from a good number of localities in Europe, several localities in Central Asia, and only one in East Asia. The distribution of known fossil Cobitis shows that Cobitis most probably had a much wider distribution range than it has today. Its present absence in most parts of Central and South Asia may be because of Cenozoic mountain-building activity in this area. The Neogene freshwater fossils from Central Asia may have had an important role to evolve the freshwater ichthyofauna of Eurasia today.

This research was supported by the National Natural Science Foundation of China (40432003 and 40662001), the State Key Laboratory of Palaeobiology and Stratigraphy (063106), and the Cypriniformes Tree of Life under the US National Science Foundation to R. Mayden (EF0431326).

See the article: Chen G, Chang M, Wang Q. DMM: Redescription of †Cobitis longipectoralis Zhou, 1992 (Cypriniformes: Cobitidae) from late early Miocene of East China. Sci China Earth Sci, 2010, 53: 945-955, doi: 10.1007/s11430-010-4003-2 